\title{
Programas de prevenção ao consumo de drogas no Brasil: uma análise da produção científica de
} 1991 a $2001^{*}$

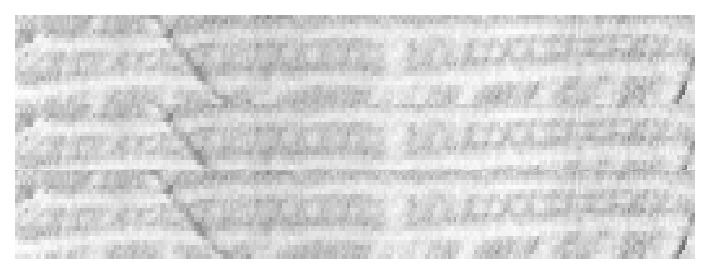

\author{
Bianca Canoletti ${ }^{1}$ \\ Cássia Baldini Soares ${ }^{2}$
}

CANOLETTI, B.; SOARES, C. B. Drug consumption prevention programs in Brazil: analysis of the scientific production from 1991 to 2001, Interface - Comunic., Saúde, Educ., v.9, n.16, p.115-29, set.2004/fev.2005.

This study deals with drug-consumption prevention programs. It presupposes that in Brazil, mainly during the 90 s, important changes occurred in prevention practices. Systematic analysis of scientific production on drug prevention programs may contribute to the evaluation of these practices in favor of both critical analysis as well as the proposition of new projects. The objective of this study was: to select and analyze studies published in Brazil, whose object was drug prevention during the period from 1991 to 2001 . Methodology was based on two procedures: 1) a bibliographic survey from on-line data bases, using the key-words drug and prevention; 2) analysis of selected studies according to: type of publication; study objective; theoretical approach and characterization of key elements of the projects. Results revealed that most of the selected studies aimed to orient drug prevention, using an approach that tends to draw closer to the conceptions and strategies of the harm reduction approach in different degrees. The publications that are concerned with the development of projects are mainly from the Rio-São Paulo axis; approximately half utilize epidemiological studies or their own mechanisms of evaluation; most aim at providing information for both students and teachers.

KEY-WORDS: Prevention; drugs; periodicals.

Este estudo trata dos programas de prevenção ao consumo de drogas. Parte-se do pressuposto de que no Brasil, a partir principalmente da década de 1990, processaram-se mudanças significativas nas práticas de prevenção. A análise sistemática da bibliografia pode contribuir com a avaliação dos rumos que essas práticas vêm tomando $e$ favorecer a crítica e a formulação de novos projetos. O objetivo deste estudo foi: levantar e analisar os trabalhos publicados no Brasil, cujo objeto é a prevenção ao consumo de drogas no período de 1991 a 2001 . A metodologia compreendeu dois procedimentos: levantamento bibliográfico em bancos de dados on-line, utilizando-se o descritor: prevenção de drogas e análise dos trabalhos selecionados, segundo: tipo de publicação; objetivo do trabalho; abordagem teórica e caracterização de outros elementos internos ao desenvolvimento dos projetos de prevenção propriamente ditos. Os resultados mostraram que a maior parte dos textos selecionados objetiva fornecer orientações para a prevenção, utilizando uma abordagem que tende em graus diferentes às concepções e estratégias da abordagem de redução de danos. Os trabalhos que dizem respeito ao desenvolvimento de projetos encontram-se majoritariamente no eixo São Paulo-Rio; cerca de metade vale-se de estudos epidemiológicos ou de mecanismos de avaliação próprios; a maior parte visa fornecer informações a estudantes e professores.

PALAVRAS-CHAVE: Prevenção; drogas; publicações periódicas.

\footnotetext{
*Artigo elaborado a partir de projeto de pesquisa financiado pelo CNPq (Proc. 016419/2002-2).

${ }^{1}$ Enfermeira, Instituto de Ortopedia e Traumatologia do Hospital das Clínicas, Faculdade de Medicina, Universidade de São Paulo. <biacanoletti@uol.com.br>
}

${ }_{2}^{2}$ Professora, Departamento de Enfermagem em Saúde Coletiva, Escola de Enfermagem, Universidade de São Paulo. <cassiaso@usp.br>

1 Rua Henri Martins, 35

Vila São Remo - São Paulo, SP

05.864-070 


\section{Introdução}

A complexidade e a magnitude do problema contemporâneo do consumo de drogas no Brasil têm sido discutidas por diferentes setores da sociedade civil $e$ do Estado (Brasil, 2003). Uma primeira análise das ações que vêm sendo tomadas para compreender e solucionar o problema mostra duas grandes fases: até o advento da Aids, quando o Brasil se caracterizava pela ausência quase total de pesquisas e pela inadequação de programas de prevenção ao consumo de drogas; e após a constatação da epidemia da Aids, quando os programas de prevenção à transmissão do HIV passaram a preocupar-se com o compartilhamento de materiais para o uso de drogas injetáveis - um dos modos de transmissão.

Assim, o Brasil até os anos 1990 era um país em que pouco se pesquisava sobre esse assunto, tendo a ausência de investigações científicas levado, para além da negligência, a equívocos relacionados à importação de modelos de outras realidades. Embora o consumo de drogas ilícitas no Brasil fosse considerado baixo em relação a outros países, continuava-se a tomar como parâmetro os números, tipos e as realidades de consumo de drogas totalmente diferentes dos nossos (Bucher, 1992; Carlini-Cotrim, 1992). Não havia programas solidamente instituídos, mas ações esparsas e descontínuas de prevenção, que refletiam o descaso do Estado e os equívocos e o desânimo das instituições públicas para tratar do tema (Bucher, 1992; Carlini-Cotrim, 1992; Soares, 1997; Noto \& Galduróz, 1999).

Numa segunda fase, quando as preocupações com a disseminação da Aids aumentaram no Brasil, procurou-se incluir nos programas de prevenção à Aids a atenção a usuários de drogas, principalmente injetáveis. Assim, no período de 1994 a 1998 começou a ser implantado no país o programa Aids1 , de responsabilidade da Coordenação Nacional de DST/Aids (CN-DST/Aids) do Ministério da Saúde, com ações que visavam conter a crescente epidemia de transmissão do HIV, utilizando-se basicamente de ações educativas, componentes de três linhas de atividades: formação de professores à distância (Projeto "Prevenir é sempre melhor"), formação de adolescentes multiplicadores e formação presencial de professores e alunos em dez capitais brasileiras, com o "Projeto Escolas" (Rua E Abramovay; 2001). A partir de 1999 até 2002 teve início a fase 2 do programa ministerial para Aids (Aids-2) na esfera estadual, abrangendo projetos de prevenção já existentes.

Por outro lado, nessa segunda fase, sofreu-se influência da Europa que já reequacionava os objetivos da prevenção ao consumo de drogas em geral, desde 1972, enfatizando o papel da educação. Desse modo, no ano de 1993, a UNESCO (Organização das Nações Unidas para a Educação a Ciência e a Cultura) passou a investir em projetos que visavam a "educação preventiva contra o abuso de drogas"; o principal exemplo é o PEDDRO - Projeto Prevenção, Educação e Drogas, em parceria com a Comissão Européia, que enfoca a informação, formação de pessoal e o intercâmbio de conhecimentos, considerando a escola, a família e a comunidade os lugares privilegiados para uma ação preventiva (Castro \& Abramovay; 2002).

Para complementar, com a intensificação do processo de globalização econômica e de incorporação dos preceitos neoliberais na América Latina $e$ particularmente no Brasil, vem ficando cada vez mais evidente a face violenta 
do narcotráfico e seus vários braços, como o tráfico de armas e a formação de quadrilhas. O Estado não imprime esforços no sentido de adequar a distribuição de renda e garantir os direitos sociais, aumentando, assim, a parcela de marginalizados. As conseqüências são sempre mais perversas nos bairros pobres, que constituem os setores privilegiados de recrutamento de narcotraficantes e de consumidores (Kaplan, 1997). Estudos (Zaluar, 1994; 1996) chamam a atenção para o fato de que os jovens de periferia contraem dívidas, envolvem-se em grupos de distribuição de drogas e outras formas de criminalidade e violência. Para agravar, argumentam, é justamente nesses espaços que a corrupção policial é maior e a polícia detém, na prática, o poder de determinar a diferença entre o traficante e o consumidor de drogas. Por todos esses motivos, ocorre o que Becker (apud Zaluar, 2002) denomina de motivação do ato desviante, ou a revolta do agente contra a ordem social e o jogo político que se apresenta, facilitando seu encontro com a droga, o tráfico e a violência (Velho, 1994; Zaluar, 2002).

Pesquisa avaliativa de âmbito nacional, das ações vinculadas ao binômio prevenção de DST/Aids e uso indevido de drogas em ambiente escolar, enfoca indicadores relacionados ao consumo de drogas injetáveis; mostra o predomínio de palestras e a focalização em disciplinas específicas entre as atividades de prevenção; $e$ aponta a ausência de gestão $e$ de institucionalização das ações, demonstrando a persistência de padrões inconsistentes nos programas e recomendando, no caso específico da prevenção ao uso indevido de drogas, reforços no esclarecimento dos jovens quanto ao uso de drogas lícitas e ilícitas (Rua \& Abramovay; 2001).

Este estudo tem a finalidade de colaborar com o conhecimento do conteúdo efetivo das mudanças nas práticas de prevenção ao consumo prejudicial de drogas no Brasil que vêm ocorrendo nos últimos anos, notadamente no período que se seguiu ao advento da aids e à promulgação do Sistema único de Saúde e do Estatuto da Criança e do Adolescente em 1990, que operacionalizam o direito à saúde e o direito das crianças e adolescentes à proteção social.

Considerando-se que a análise sistemática da bibliografia referente aos programas de prevenção desenvolvidos no Brasil possa contribuir para a avaliação dos rumos que as práticas relacionadas têm tomado e portanto favorecer a crítica e a formulação de novos projetos, os objetivos deste estudo foram: levantar os trabalhos publicados no Brasil, que tomaram como objeto a prevenção ao consumo de drogas, entre os anos $1991 \mathrm{e}$ 2001; analisar os trabalhos relacionados diretamente ao desenvolvimento de programas de prevenção.

Considerações teóricas: o campo da prevenção ao consumo de drogas

Neste trabalho, considera-se que a droga é uma mercadoria e que o consumo de drogas deve ser analisado à luz da estrutura e dinâmicas do modo de produção capitalista, que conformam os contextos da sociedade contemporânea. Assim, trata-se de reconhecer que o consumo de drogas está submetido às possibilidades de reprodução social dos indivíduos, 
famílias e classes ou grupos sociais, bem como reflete as conseqüências das políticas sociais públicas adotadas pelo Estado. Portanto, a política e os programas de prevenção ao consumo de drogas deveriam estar voltados tanto para mudanças em contextos de socialização $e$ interação dos indivíduos, delimitados e específicos a sua condição de classe, quanto para mudanças estruturais mais gerais que melhorem a distribuição da renda e o acesso aos bens socialmente produzidos (Soares, 1997).

Toma-se também como referência teórica neste trabalho uma abordagem educacional emancipatória, considerada potente para formar sujeitos com capacidade crítica, habilitados para propor mudanças, capazes de refletir sobre suas escolhas e não resignados a aceitar, como único caminho, aquele do prejuízo relacionado ao consumo de drogas (Soares, 1997).

Nesse sentido, concorda-se aqui com os autores que defendem que os programas de prevenção deveriam seguir princípios de valorização da vida, muito mais do que exercitar olhares moralistas e repressivos (Bucher, 1992; Brasil, 1994), fortalecendo, com isso, os indivíduos e grupos sociais para compreender a teia causal do consumo de drogas (Soares, 1997), que compõem uma parcela da vertente crítica à política da guerra ou combate às drogas, que reúne especialistas de diversas áreas em torno da tendência à adoção de estratégias de redução de riscos/danos (Bastos, 1996).

A literatura mostra, no entanto, que historicamente o modelo de prevenção hegemônico tem sido o do combate ou guerra às drogas, modelo que teve sua maior expressão por volta de 1989, nos Estados Unidos, sob o governo de George Bush que afirmava que a prioridade dos programas de prevenção era reduzir nacionalmente o consumo global do uso de drogas - o primeiro uso, o uso ocasional, o uso regular e os quadros de dependência. Segundo documento divulgado em 1989, os usuários ocasionais de drogas são considerados contaminantes dos não usuários, e por isso um perigo nacional (Carlini-Cotrim, 1992).

Nessa abordagem, para alcançar o único objetivo - abstinência de qualquer consumo de drogas ilícitas - são propostas: a persuasão moral, que intenta que os indivíduos não "queiram" usar drogas, e a repressão, que objetiva que os indivíduos temam as conseqüências, principalmente legais, deste consumo. Finalmente, esta ideologia concentra em si a idéia de intolerância, o desejo de banir completamente as drogas ilícitas da sociedade (Carlini-Cotrim, 1992).

Uma revisão mostra que a abordagem de redução de riscos/danos, apesar de ter origem em práticas que remontam a 1926, na Inglaterra, foi abandonada por longo tempo, somente ressurgindo no cenário da saúde pública por conta da epidemia da Aids. Esse modelo pondera que se o consumo de drogas é impossível de ser eliminado por completo, a melhor maneira de agir seria reduzindo os problemas que podem surgir em decorrência. Ainda, pela ótica da redução de riscos/danos, as drogas lícitas como álcool, tabaco e medicamentos são as que acarretam mais problemas à sociedade, devendo ser também objeto da prevenção (Soares, 1997).

Além disso, Carlini-Cotrim (1992) chama a atenção para a ponderação de alguns defensores dessa perspectiva, de que não se deveria interferir no direito que o cidadão tem sobre seu próprio corpo. Em tese, o uso de drogas 
propriamente dito não necessariamente interferiria negativamente sobre a sociedade. Sendo assim, a competência do Estado sobre o consumo de drogas deveria circunscrever-se às ações que interferem diretamente na sociedade, isto é, os danos relacionados à saúde e à violência principalmente. Portanto, seria sobre esses danos, e não sobre o arbítrio dos cidadãos sobre si mesmos que deveriam recair as políticas de prevenção ao uso de drogas; o que se configuraria em programas realistas, eficientes, eticamente corretos, $e$ providos de credibilidade.

A história brasileira dos programas de prevenção de drogas mostra nítida aderência à abordagem de guerra às drogas, embora mais recentemente algumas práticas mostrem-se simpáticas à perspectiva da redução de riscos/ danos, agregando-se em maior ou menor grau aos pressupostos, à ideologia, aos objetivos e às estratégias desse movimento (Soares E Jacobi, 2000).

As avaliações dos programas delineados a partir da abordagem da guerra às drogas mostram clara ineficiência e pelo contrário suscitam a curiosidade e leviandade no trato de um assunto tão complexo (Carlini-Cotrim, 1992; Bucher, 1992). Já quando se fala em avaliação de programas de redução de riscos/danos esbarra-se em políticas públicas de saúde, na legislação e na própria realidade do local (Soares, 1997).

Além de sua importância na avaliação dos programas de prevenção ao consumo de drogas, o conhecimento da realidade local é imprescindível para o sucesso de qualquer ação, uma vez que determina as estratégias que devem ser utilizadas (Soares \& Jacobi, 2000).

A participação dos jovens na elaboração e desenvolvimento das ações de prevenção pode tornar os programas mais atraentes, diminuindo o risco de sua inoperância. A participação dos jovens reflete-se na responsabilidade destes perante as ações que desenvolvem, bem como perante seus pares, conferindo um tom realista à prevenção. Merece atenção especial sua participação como multiplicadores por ser uma prática que inadvertidamente pode responsabilizar o jovem por desenvolver um trabalho que cabe ao Estado, no qual ele entra como colaborador e não como trabalhador (Soares \& Jacobi, 2000).

\section{Procedimentos metodológicos}

Este estudo constitui pesquisa bibliográfica (Gil, 1991), realizada em bancos de dados disponíveis on line, utilizando o descritor prevenção de drogas, aceito pelo sistema Ciências da Saúde adotado pela BIREME. Foram utilizadas, ainda, palavras-chave de significado próximo ao descritor, na intenção de resgatar os trabalhos que, embora tratassem da prevenção de drogas, não estivessem utilizando descritores padronizados (projeto de prevenção de drogas, programas de prevenção de drogas, substâncias psicotrópicas).

Os bancos de dados pesquisados foram basicamente três: CEBRID Centro Brasileiro de Estudos sobre Drogas Psicotrópicas, DEDALUS - Banco de Dados Bibliográficos da USP, e Biblioteca Virtual em Saúde. A Biblioteca Virtual em Saúde é composta, por sua vez, por diversos outros bancos de dados, dos quais foram utilizados: LILACS - Literatura Latino-Americana e do Caribe em Saúde Pública, ADSAúDE - Administração de Serviços de Saúde, 
MS - Acervo da Biblioteca do Ministério da Saúde, FSP - Acervo da Biblioteca da Faculdade de Saúde Pública da USP, e ENSP - Acervo da Biblioteca da Escola Nacional de Saúde Pública.

Após o levantamento, foi realizada leitura exploratória da bibliografia, selecionando-se os artigos pertinentes ao objeto pesquisado com base nos seguintes critérios: ano de publicação entre 1991 e 2001; publicação não restrita a resumo; referir-se a drogas psicoativas (lícitas ou ilícitas) e não a outras drogas; não se tratar de texto da área de tratamento ou da área de classificação de drogas; não se tratar de catálogo; estar publicado em língua portuguesa, referindo-se a aspectos brasileiros.

O passo seguinte à seleção dos artigos foi classificá-los segundo ano e tipo de publicação, isto é, se se tratava de artigo de revista, manual ou documento oficial, manual não oficial, livro ou capítulo, dissertação, tese, entre outros.

A seguir, foi realizada leitura analítica dos textos selecionados, classificando-os segundo a abordagem em que se baseavam. Foram utilizadas quatro categorias para proceder a essa classificação: combate ou guerra às drogas, redução de riscos/danos ampla, transição e redução de danos para prevenção da Aids (Quadro 1). A construção dessas categorias baseouse no estudo de Soares \& Jacobi (2000). Embora voltada à área de tratamento, não se pode deixar de fazer alusão também à publicação de Moreira \& Silveira (2003), que compara a política de guerra às drogas ao movimento da redução de danos, a partir de uma síntese realizada por outros autores.

Quadro 1 - Categorias de análise da bibliografia segundo a abordagem utilizada na prevenção. São Paulo, 2003.

\begin{tabular}{|l|l|}
\hline $\begin{array}{l}\text { Combate ou guerra às } \\
\text { drogas }\end{array}$ & $\begin{array}{l}\text { A droga é considerada causa dos problemas dos indivíduos; idealiza-se uma sociedade } \\
\text { livre de drogas, aceitando-se somente a abstinência como meta; as informações são } \\
\text { tendenciosas; os métodos são alarmistas, amedrontadores e generalizadores; respon- } \\
\text { sabiliza-se o indivíduo pelo consumo e se requer exclusivamente dele os esforços para } \\
\text { mudança de comportamento. }\end{array}$ \\
\hline $\begin{array}{l}\text { Redução de riscos/ } \\
\text { danos ampla }\end{array}$ & $\begin{array}{l}\text { Crítica explícita à política de guerra às drogas; a demanda e a oferta de drogas lícitas ou } \\
\text { ilícitas fazem parte do processo histórico e social contemporâneo; os objetivos da } \\
\text { prevenção abrangem qualquer avanço que minimize os prejuízos que possam advir do } \\
\text { consumo de drogas; admite-se diferentes tipos de uso; a educação deve despertar a } \\
\text { crítica, com projetos de fortalecimento dos indivíduos e grupos ou classes sociais; os } \\
\text { métodos são participativos e inclusivos; os projetos são específicos para cada situação. }\end{array}$ \\
\hline Transição & $\begin{array}{l}\text { O uso de drogas é em geral tomado como disfuncional, multifatorial e identificado com os } \\
\text { pressupostos da prevenção primária; há superposição de perspectivas teórico- } \\
\text { metodológicas; objetiva-se prevenir ao mesmo tempo o uso, o uso indevido ou o abuso; } \\
\text { apresenta comunalidades com a abordagem da redução de risco/danos, principalmente } \\
\text { no que se refere à: aceitação de que o consumo de drogas é histórico e processual; } \\
\text { utilização de informação científica e ênfase na formação educacional e na utilização de } \\
\text { métodos participativos. }\end{array}$ \\
\hline $\begin{array}{l}\text { Redução de danos } \\
\text { aplicada à aids }\end{array}$ & $\begin{array}{l}\text { O objetivo central é a prevenção da transmissão do HIV pelo compartilhamento de } \\
\text { material de uso de drogas injetáveis. }\end{array}$ \\
\hline
\end{tabular}


Os textos também foram classificados segundo o objetivo a que se propunham: orientação para a prevenção (artigos de reflexão e análise) ou relato do desenvolvimento de projeto de prevenção (artigos de estudo de caso, em qualquer fase), conforme descrito no quadro 2.

Quadro 2 - Categorias de análise da bibliografia segundo o objetivo da publicação. São Paulo, 2003.

\begin{tabular}{|l|l|}
\hline Orientação & $\begin{array}{l}\text { A linha mestra é a análise crítica acerca da prevenção de drogas, } \\
\text { orientações e propostas para o desenvolvimento de programas. }\end{array}$ \\
\hline Desenvolvimento do projeto & $\begin{array}{l}\text { Diz respeito àqueles textos que descrevem projetos de prevenção em } \\
\text { fase de proposta, implantação, desenvolvimento e/ou avaliação. }\end{array}$ \\
\hline
\end{tabular}

Após esta fase classificatória, foram analisados aqueles estudos que tratavam do desenvolvimento de projetos de prevenção propriamente ditos. Essa análise abrangeu aspectos como local e ano de implantação do projeto, população a que o projeto se destinava, estratégias adotadas, presença de estudo epidemiológico prévio, inclusão da formação de multiplicadores, processo de avaliação, e ainda se havia proposta de distribuição de materiais preventivos, como agulhas, seringas ou preservativos.

\section{Resultados e análise}

\section{Seleção das publicações}

Dos sete bancos de dados pesquisados, o Lilacs apresentou a maior freqüência de trabalhos mencionados (447 artigos), seguido pelo CEBRID com 241 artigos. No total, foram encontradas 928 menções, sendo selecionados, numa primeira etapa, 194 trabalhos (tabela 1).

Tabela 1 - Distribuição dos trabalhos segundo os bancos de dados consultados. São Paulo, 2002.

\begin{tabular}{ccc}
\hline $\begin{array}{c}\text { Bancos de dados } \\
\text { on line }\end{array}$ & $\begin{array}{c}\text { Trabalhos } \\
\text { encontrados }\end{array}$ & $\begin{array}{c}\text { Trabalhos } \\
\text { selecionados }\end{array}$ \\
\hline CEBRID & 241 & 58 \\
DEDALUS & 132 & 36 \\
LILACS & 447 & 46 \\
AdSaúde & 49 & 19 \\
MS & 11 & 9 \\
FSP-USP & 42 & 23 \\
ENSP & 6 & 3 \\
\hline Total & 928 & 194 \\
\hline
\end{tabular}

Mediante leitura dos resumos selecionados, eliminaram-se as repetições de artigos provenientes de publicações indexadas em diferentes bancos. Assim, foi possível obter uma lista de 133 publicações para análise e classificação. Conservaram-se as publicações distintas, ainda que, algumas vezes, se referissem ao mesmo projeto.

O tipo de publicação mais freqüentemente encontrado foi livro (36 $27,1 \%)$, seguido de artigos de periódicos (23 - 17,3\%). Além de dez teses 
ou dissertações $(7,5 \%)$, também foram encontradas diversas publicações institucionais (documentos oficiais e manuais - $48-36,1 \%$ ).

$\mathrm{O}$ ano de 1992 foi o que apresentou maior freqüência de textos, com 24 publicações (18\%). Já 1998 teve a menor freqüência, com apenas sete trabalhos publicados $(5,3 \%)$.

\section{Objetivo das publicações}

Os textos selecionados foram requisitados nas respectivas bibliotecas, obtendo-se um total de 122 (92\%). Muitos deles, não acessados, encontram-se no acervo da Biblioteca do Ministério da Saúde e aparentemente sugerem orientações para o desenvolvimento de programas de prevenção.

Os 122 textos selecionados e obtidos foram primeiramente classificados segundo seu objetivo, a partir de duas categorias distintas (tabela 2). $\mathrm{O}$ ano de 1992 apresentou a maior freqüência de publicações com o objetivo de orientação ou análise crítica (21-17,2\%). Em contrapartida, a menor produção (3-2,5\%) foi constatada no ano de 1991, seguido pelo ano de 2001 (5-4,1\%). Já os textos de relato de desenvolvimento de projeto se apresentaram mais freqüentes nos anos de 1993 (4-3,3\%) e 1997 (5$4,1 \%)$, sendo que os anos de 1994 e 1998 apresentaram, cada qual, um $(0,8 \%)$ registro de texto com este objetivo.

Tabela 2 - Distribuição dos textos selecionados segundo objetivo. São Paulo, 2003.

\begin{tabular}{lcc}
\hline Objetivo & N & $\%$ \\
\hline Orientação & 94 & 77 \\
Desenvolvimento do projeto & 28 & 23 \\
\hline Total & 122 & 100 \\
\hline
\end{tabular}

\section{Abordagem que orientou a prevenção}

A distribuição dos textos analisados conforme a utilização de abordagens preventivas diversas está demonstrada na tabela 3. Pode-se perceber que mais da metade dos textos (63-51,6\%) apresentou-se na categoria transição, e que a abordagem da redução de riscos/danos ampla representou $23,0 \%$ do total (28 textos). A categoria redução de riscos/ danos relacionada à prevenção da aids foi apontada em $18,9 \%$ dos trabalhos analisados (23). A abordagem do combate às drogas constitui uma minoria (6,6\% - 8 publicações) na década de 1990.

Tabela 3 - Distribuição dos textos selecionados segundo a abordagem preventiva. São Paulo, 2003.

\begin{tabular}{lcc}
\hline Abordagem & $\mathbf{N}$ & $\%$ \\
\hline Transição & 63 & 51,6 \\
Redução de riscos/danos ampla & 28 & 23 \\
Redução de riscos/danos aplicada à aids & 23 & 18,9 \\
Combate às drogas & 08 & 6,6 \\
\hline Total & 122 & 100 \\
\hline
\end{tabular}


Características dos relatos de desenvolvimento de projetos

Os 28 textos selecionados como relato de desenvolvimento de projeto foram alvo de uma análise mais aprofundada, cumprindo um dos objetivos deste estudo.

O Estado brasileiro de origem dos projetos de prevenção ao consumo de drogas que mais se destacou foi São Paulo (oito), seguido pelo Rio de Janeiro (seis). Havia também representação dos Estados do Rio Grande do Sul (dois), e Minas Gerais, Bahia, Espírito Santo, Paraná e Ceará contaram cada um com um relato de projeto. Seis publicações diziam respeito a programas de âmbito nacional desenvolvidos pelo Ministério da Saúde e em uma não havia referência ao local do projeto.

No que diz respeito aos componentes de um projeto de prevenção estudo epidemiológico preliminar, objetivo de fornecer algum tipo de informação sobre drogas, participação/formação de agentes de prevenção/ multiplicadores e processo de avaliação formal, em qualquer etapa - a amostra se distribuiu da seguinte maneira: 25 projetos incluíam o fornecimento ou discussão de informação científica sobre drogas em alguma etapa do projeto; 17 indicaram preocupações ou previram atividades de avaliação formal; 15 faziam referência à participação de agentes de prevenção ou à formação de multiplicadores, e 11 dos projetos analisados indicaram ter partido de estudos epidemiológicos preliminares (tabela 4).

Tabela 4 - Distribuição dos projetos segundo menção de seus componentes. São Paulo, 2003.

\begin{tabular}{ll}
\hline Componentes dos projetos & N \\
& 28 \\
\hline Informação sobre drogas & 25 \\
Processo de avaliação formal & 17 \\
Participação de multiplicadores & 15 \\
Estudo epidemiológico preliminar & 11 \\
\hline
\end{tabular}

O público-alvo dos projetos localiza-se principalmente na escola, focalizando estudantes (dez) e professores (nove), quase sempre concomitantemente, com poucos envolvendo outros membros da escola, inclusive pais (três), e apenas um desenvolvendo atividades com estudantes universitários. Alguns objetivavam atingir moradores de um determinado território ou "comunidade" (cinco), usuários de drogas injetáveis (seis) ou apenas usuários de drogas (três), profissionais de saúde (quatro) e jovens "de rua" e/ou "em risco" (um). Vale notar que alguns projetos referiram a existência de alguns subprojetos e, nesse caso, todos os subgrupos foram considerados.

Os projetos estudados indicaram a utilização de várias técnicas pedagógicas concomitantemente: dinâmica de grupo e discussão empataram em primeiro lugar (oito), seguidas por oficinas (sete). Em terceiro lugar estavam a utilização e elaboração de material informativo e recursos audiovisuais (seis). A aplicação de questionários ou entrevistas foi utilizada por cinco projetos. Jogos e estudo dirigido foram estratégicos em quatro. Em três, cursos, teatros e debates foram também utilizados. Apenas dois 
projetos referiram palestras, $e$, finalmente, treinamento à distância $e$ rádio foram indicados em um projeto.

Por fim, procurou-se reconhecer a estratégia de distribuição de material preventivo. Os materiais distribuídos pelos projetos eram: preservativos (cinco), folhetos informativos (quatro), seringas e agulhas descartáveis (quatro) e hipoclorito de sódio (três).

\section{Discussão}

A busca bibliográfica sobre prevenção de drogas nos bancos de dados atuais mostrou que, apesar de se levantar uma quantidade significativa de artigos, somente uma parcela bastante reduzida diz respeito ao desenvolvimento de projetos de prevenção propriamente dito, alguns deles, inclusive, referindose ao mesmo projeto, como é o caso de algumas publicações de projetos ministeriais ou como é o caso de teses que foram posteriormente publicadas em forma de artigo.

Como foi possível observar, o ano de 1992 apresentou a maior freqüência de publicações. Sabe-se que no final da década de 1980 e início dos anos 1990 a discussão social em torno da aids foi bastante fortalecida tanto pela academia quanto pelas ONGs preocupadas com a disseminação do HIV, forçando órgãos governamentais - Ministério da Saúde, especialmente a CN-DST/Aids, criada para conter a epidemia de Aids, e Ministério da Educação - a se posicionarem. Ao mesmo tempo, diversas organizações internacionais passaram a financiar projetos na área de prevenção do HIV relacionada ao uso de drogas, entre elas o Programa das Nações Unidas para o Controle Internacional de Drogas (UNDCP), o Banco Mundial, os governos da Alemanha, França e Japão, o Centre for Disease Control (CDC), a Comunidade Européia e a Agência Americana para o Desenvolvimento Internacional (USAID).

$\mathrm{O}$ estudo mostrou que a maior parte das publicações apresentou como finalidade orientar para a prevenção. Apesar de já se ter passado quase uma década, o documento do Ministério da Educação e Cultura (MEC), publicado em 1994, concorda que são raros os trabalhos em que a prevenção ultrapassa o nível da discussão e exortação.

A abordagem do combate às drogas - que se deixa transparecer na maior parte das vezes por uma linguagem bélica - representa uma minoria entre as aproximações teóricas e práticas utilizadas nos estudos selecionados, o que provavelmente seja fruto de uma mudança de discurso do Estado e da sociedade civil, principalmente do setor acadêmico, que passa, durante a década de 1990, a censurar tanto os discursos alarmistas e estritamente repressivos, como a redução do problema das drogas a apenas um de seus ângulos - a droga propriamente dita -, negligenciando tanto os contextos sociais que favorecem um uso prejudicial quanto as pessoas que utilizam drogas (Bucher, 1992; Carlini-Cotrim, 1992; Soares \& Jacobi, 2000).

A significativa freqüência de textos que se encaixaram, em maior ou menor grau, na abordagem aqui denominada de transição e aqueles relacionados à redução de danos - ampla e relativa à prevenção do HIV/Aids - demonstra que pesquisadores e formuladores de políticas passaram a tomar como objeto a crescente epidemia de Aids, o que por sua vez

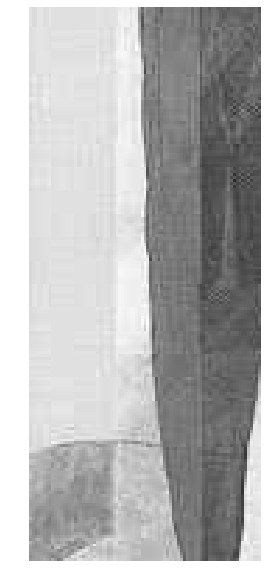


fomentou a procura de novas formas de fazer prevenção. Nesse contexto, o consumo de drogas que era visto como a "escolha" de alguns - normalmente marginais -, passou a ser visto como um acompanhante indesejável do HIV, que pode ser transmitido pelo compartilhamento de seringas e por relações sexuais não protegidas (Bastos, 1996).

A maioria dos 28 relatos de projetos encontrados no estudo foi desenvolvida no eixo São Paulo - Rio de Janeiro. Isto se deve ao fato de que estes dois Estados representam juntos a maior força econômico-política da federação brasileira e, por conseguinte, onde se encontram o maior número de instituições - universidades, ONGs - do país (UNDCP, 1994).

A criação e desenvolvimento de políticas e programas de prevenção ao consumo de drogas, como todas as demais, são conseqüencia de decisões políticas, estando, pois, sujeitas a pressões e vulneráveis às reviravoltas políticas (Weiss, 1982). Como resposta ao contexto de pressões internacionais e de grupos organizados no país, com relação principalmente à crescente transmissão do HIV, o Ministério da Saúde passou a se posicionar também perante a necessidade de políticas de prevenção ao consumo de drogas, criando, na década de 1990, a CN-DST/Aids, incumbida de impulsionar o desenvolvimento de um conjunto de projetos, também com relação às drogas (Rua \& Abramovay, 2001) - objeto de três dos textos analisados -, e cuja influência está presente na maior parte dos projetos analisados, encontrando apoio nos centros de referência (NEPAD/UERJ, CETAD/UFBa) ou outros núcleos ligados a universidades e a secretarias municipais e estaduais de saúde e educação.

O estudo levantou, ainda, a presença de alguns componentes considerados indispensáveis ao desenvolvimento de projetos de prevenção. O primeiro deles diz respeito à realização de estudo epidemiológico preliminar. O planejamento de qualquer programa deve ser baseado na avaliação inicial da situação sobre a qual se pretende interferir, determinando quais ações serão necessárias para atingir as metas propostas e evitando importar dados de realidades diferentes. O levantamento epidemiológico auxilia na avaliação da extensão do problema de acordo com as características da região (MEC, 1994). Conforme foi visto, menos da metade dos programas analisados fizeram referência a um estudo epidemiológico preliminar, estando os demais projetos sujeitos ao descompasso entre a realidade local e os objetivos $e$ as estratégias adotadas.

Bucher (1992) discute a importância de se fornecer informação correta sobre drogas. A informação subsidia a reflexão crítica acerca do tema, possibilitando um diálogo aberto e confiável entre os sujeitos da prevenção. Representa um dos componentes dos programas de educação preventiva $e$ não a educação propriamente dita. A informação eficiente é aquela que possibilita uma análise em relação às opções possíveis, quais sejam: o uso racional e responsável de drogas ou os benefícios da abstinência. A informação alarmista e repressiva ou a "pedagogia do terror" mostra-se ineficiente e poderia até mesmo suscitar nos jovens o desejo de desafiar o mal e afrontar o que é proibido (Bucher, 1992; Carlini-Cotrim, 1992).

A capacitação e participação de agentes de saúde ou multiplicadores nos projetos é também um componente importante e complexo. Importante 
porque permite que o grupo da população a que o projeto se destina principalmente usuários de drogas injetáveis e jovens adolescentes - possam ser abordados mais diretamente e numa situação de transversalidade, pelos pares (Bastos, 1996). O jovem pode trazer ao projeto problemas reais $e$ soluções concretas; é portanto um sujeito social capaz de mudar o que está instituído (Moraes, 2003).

Complexo pois envolve a possibilidade de se incorrer no erro de transferir para o multiplicador a responsabilidade da prevenção, sem no entanto dar subsídios para que este possa desenvolver as atividades. Isso se traduz em dois aspectos: o primeiro diz respeito à falta de apoio financeiro, uma vez que os projetos de multiplicadores são essencialmente destinados a grupos com dificuldade de reprodução social, necessitando trabalhar para ajudar na manutenção da vida (moradia, alimentação, saúde, educação). O segundo aspecto remete à insuficiência da supervisão que visa apoiar os multiplicadores, gerando insegurança no desenvolvimento de suas atividades e um sentimento de que se "aprende mais do que ensina" (Moraes, 2003).

Finalmente, é preciso discutir que, apesar da importância do processo formal de avaliação, ele não vem sendo explicitado nas publicações. A avaliação de projetos de prevenção compreende ponderar sobre resultados que serão atingidos a médio e longo prazo, por transformações de difícil mensuração, $e$ deve ser parte integrante do planejamento de qualquer projeto, como atividade constante ao longo das atividades. O processo de avaliação funciona como dispositivo auto-regulador das ações e resultados alcançados ou não, buscando a qualidade e instrumentalizando ações futuras (MEC, 1994; Aggleton, 1995).

Além disso, especialistas em avaliação de projetos chamam a atenção para o fato de que futuros financiamentos estão condicionados ao sucesso das atividades avaliadas (Aggleton, 1995). A avaliação fornece ainda argumentos para a continuidade ou desdobramento de determinados projetos, como foi o caso dos Aids-1 e Aids-2, financiados pelo governo brasileiro e Banco Mundial (Rua \& Abramovay, 2001).

A maioria dos projetos analisados tem por objetivo atingir a escola (alunos $e$ professores), influenciados pela produção importante de especialistas que advogam o espaço escolar como privilegiado para o desenvolvimento da educação preventiva (Bucher, 1992; Carlini-Cotrim, 1992; Soares, 1997). Desde 1994 o Ministério da Saúde, especialmente a CN-DST/Aids e área de saúde mental, e o MEC procuram desenvolver atividades preventivas nas escolas (Rua \& Abramovay, 2001).

Há projetos voltados à população em geral, atendendo recomendação do MEC (1994), que considera a atuação, para além da escola, em outros espaços de socialização no bairro. Outros projetos envolvem profissionais de saúde que teriam como responsabilidade fornecer informações corretas e imparciais acerca da questão, influenciando negativa ou positivamente na determinação da iniciativa do usuário de drogas em procurar auxílio, se achar pertinente, questões hoje reconhecidas pela política oficial (Brasil, 2003).

Constatou-se que as técnicas mais amplamente utilizadas pelos projetos analisados foram aquelas que buscam problematizar o consumo de drogas $e$ levar a uma reflexão crítica, desmistificando o mal da droga em si e auxiliando na tomada de decisão segura, sadia e informada, de acordo com o contexto 
específico de cada sujeito, conforme defendido por especialistas (Bucher, 1992; Carlini-Cotrim, 1992; Brasil, 2000). Diferentemente, Rua e Abramovay (2001), ao analisarem o desenvolvimento de projetos- piloto em escolas públicas monitoradas pelo Ministério da Saúde, notam a persistência da palestra, realizada principalmente por agentes extra-escolares, como médicos e policiais.

É possível que essa diferença se explique porque os projetos aqui analisados refletem idéias pioneiras e exemplares, condicionadas pelas exigências inerentes aos processos da publicação e guardando considerável distância da realidade social mais ampla, seja escolar, seja no bairro.

Finalmente, percebe-se que é rara a adoção de estratégias de distribuição de materiais preventivos pelos projetos. Apesar de notar-se uma mudança em relação à abordagem utilizada na prevenção, não se incorpora a distribuição de materiais que efetivariam algumas das estratégias de redução de danos. Isso pode ser tanto fruto dos impedimentos legais, que apenas nos últimos anos da década de 1990 passaram a ser afastados, como pode advir do próprio receio da população de que se houver uma distribuição de seringas e agulhas descartáveis, por exemplo, a conseqüência pode ser um aumento do número de usuários de drogas injetáveis.

\section{Conclusões}

Pode-se perceber que, apesar do alastrado temor social em relação às drogas, a sociedade civil, e notadamente o Estado, somente procuraram novas alternativas para a prevenção do consumo prejudicial de drogas a partir da disseminação do HIV. Grave e fatal, a Aids impôs uma preocupação social, antes de foro individual, de se preservar as pessoas dos danos que podem advir do exercício da própria sexualidade, quando desprotegida. Em decorrência, a sociedade começou a aceitar metas diferentes também para a prevenção ao consumo de drogas, não se limitando à da abstinência propriamente dita.

A produção científica acerca do tema drogas é abundante no que diz respeito aos aspectos farmacológicos da droga em si, $e$ ao tratamento da dependência, como tradicionalmente o tema vem sendo tratado na área da saúde (Soares \& Campos, 2003). A parcela que se refere à prevenção, pelo menos na década de 1990, consiste consideravelmente de reflexões acerca das avaliações negativas dos programas de prevenção que seguiam os pressupostos $e$ os métodos da guerra às drogas, desenvolvidos em todo o mundo. Alguns estudos consistem de levantamentos epidemiológicos preocupados em diagnosticar níveis de consumo em populações específicas. Ambos os casos fundamentam um conjunto de orientações a respeito de como proceder para desenhar ou implementar programas de prevenção.

Essa produção parece refletir um estágio de experimentação em que se produzem orientações e propostas. Somente os centros de excelência na área $e$ instituições governamentais, notadamente de esfera federal, conseguem relatar o desenvolvimento de programas de prevenção propriamente ditos.

Sabe-se que há um descompasso entre as proposições e programas críticos e inovadores advindos dos chamados núcleos acadêmicos e a realidade dos textos oficiais (Bucher \& Oliveira, 1994), e das propagandas veiculadas pela mídia e dirigidas a adolescentes (Ribeiro et al., 1998). 
Resguardadas as limitações de um trabalho de natureza classificatória limitante por si mesmo diante de um objeto tão complexo - pode-se dizer que as estratégias utilizadas pelos programas analisados se encontram agregadas majoritariamente numa categoria transitória entre o modelo hegemônico (guerra às drogas) e o novo modelo em construção (aqui chamado de redução de danos ampla); por um lado, por incorporar mudanças de orientação da sociedade em relação ao consumo de drogas; e por outro, por ser este um discurso "politicamente" mais correto do que o discurso estritamente repressivo, que de uma maneira geral continua sendo bastante expressivo no cotidiano dos serviços.

\section{Referências}

AGGLETON, P. Monitoramento e avaliação de educação em saúde e promoção da saúde voltada para o HIV/Aids. In: CZERESNIA, D., SANTOS, E.M., BARBOSA, R.H.S., MONTEIRO, S. (Orgs). Aids: pesquisa social e educação. São Paulo: Hucitec; Rio de Janeiro: Abrasco, 1995. p.193-206.

BASTOS, F. I. Ruína e reconstrução: aids e drogas injetáveis na cena contemporânea. Rio de Janeiro: Relume-Dumará/ABIA/IMS/UERJ, 1996.

BRASIL. Ministério da Educação e do Desporto. Secretaria de projetos educacionais especiais. Diretrizes para uma política educacional de prevenção ao uso de drogas. Brasília, 1994.

BRASIL. Ministério da Saúde. Coordenação Nacional de DST/Aids. Manual do multiplicador: adolescentes. Brasília, 2000.

BRASIL. Ministério da Saúde. Secretaria Executiva. Secretaria de Atenção à Saúde. Coordenação Nacional DST/Aids. A política do Ministério da Saúde para atenção integral a usuários de álcool e outras drogas. Brasília, 2003.

BUCHER, R. Drogas e drogadição no Brasil. Porto Alegre: Artes Médicas, 1992.

BUCHER, R.; OLIVEIRA, S. O discurso do "combate às drogas" e suas ideologias. Rev. Saúde Pública, v.28, n.2, p.137-45,1994.

CARLINI-COTRIM, B. H. A escola e as drogas: realidade brasileira e contexto internacional. 1992. Tese (Doutorado) - Departamento de Psicologia Social, Pontifícia Universidade Católica, São Paulo.

CASTRO, M. G.; ABRAMOVAY. M. Drogas nas escolas. Brasília: UNESCO, Coordenação DST/ Aids do Ministério da Saúde, Secretaria de Estado dos Direitos Humanos do Ministério da Justiça, CNPq, Instituto Ayrton Senna, UNAIDS, Banco Mundial, USAIDS, Fundação Ford, CONSED, UNDIME, 2002.

GIL, A.C. Como elaborar projetos de pesquisa. São Paulo: Atlas, 1991.

KAPLAN, M. Tráfico de drogas, soberania estatal, seguridad nacional. Sistema, n.136, p.43-61, 1997.

MORAES, T. C. L. Estudo de um programa de prevenção em DST/Aids: a presença do jovem. 2003. Dissertação (Mestrado) - Faculdade de Educação, Universidade de São Paulo, São Paulo.

MOREIRA F.; SILVEIRA, D. Posicionamento do Programa de Orientação e Atendimento a Dependentes (PROAD). J.I Bras. Psiquiatr.,v.52, n.5, p.366-70, 2003.

NOTO, A R.; GALDURÓZ, J.C.F. O uso de drogas psicotrópicas e a prevenção no Brasil. Ciênc. Saúde Coletiva, v.4, n.1, p.145-54, 1999.

RIBEIRO, T.W.; PERGHER, N.K.; TOROSSIAN, S.D. Drogas e adolescência: uma análise da ideologia presente na mídia escrita destinada ao grande público. Psicol. Reflex. Crít., v.11, n.3, p.421-30, 1998.

RUA, M.G.; ABRAMOVAY, M. Avaliação das ações de prevenção as DST/Aids e uso indevido de 
drogas nas escolas de ensino fundamental e médio em capitais brasileiras. Brasília: UNESCO/Ministério da Saúde/Grupo Temático UNAIDS/UNDCP, 2001.

SOARES, C.B. Adolescentes, drogas e AIDS: avaliando a prevenção e levantando necessidades. 1997. Tese (Doutorado) - Faculdade de Educação, Universidade de São Paulo, São Paulo.

SOARES, C. B.; JACOBI, P. R. Adolescentes, drogas e aids: avaliação de um programa de prevenção escolar. Cad. Pesq., n.109, p.213-37, 2000.

SOARES, C.B.; CAMPOS, C.M.S. A responsabilidade da universidade pública no ensino da prevenção do uso prejudicial de drogas. Mundo da Saúde, v.28, n.1, p.110-5, 2004.

UNDCP. Programa Nacional das Nações Unidas para o Controle Internacional de Drogas. Prevenção ao abuso de drogas com ênfase especial na prevenção do HIV entre usuários de drogas intravenosas no Brasil. Brasília: Ministério da Saúde, 1994.

VELHO, G. A dimensão cultural e política dos mundos das drogas. In: ZALUAR, A. (Org.) Drogas e cidadania: repressão ou redução de danos. São Paulo: Brasiliense, 1994. p.23-9.

WEISS, C. Pesquisa avaliativa no contexto político. In: GOLDBERG M.A.A.; SOUZA, C.P. (Orgs.)

Avaliação de programas educacionais: vicissitudes, controvérsias, desafios. São Paulo: EPU, 1982. p.23-8.

ZALUAR, A. Introdução: drogas e cidadania. In: ZALUAR, A. (Org.) Drogas e cidadania: repressão ou redução de danos. São Paulo: Brasiliense, 1994. p.7-21.

ZALUAR, A. Da revolta ao crime S. A. São Paulo: Moderna, 1996.

ZALUAR, A. Um panorama no Brasil e no mundo. Ciênc. Hoje, v.31, n.181, p.32-5, 2002.

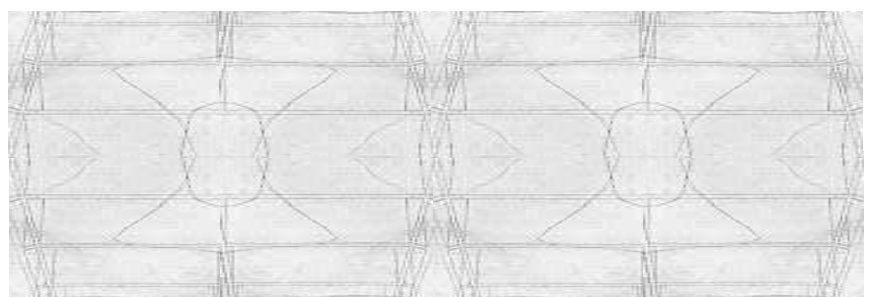

CANOLETTI, B.; SOARES, C. B. Programas de prevención del consumo de drogas en Brasil: un análisis de la producción científica de 1991 a 2001, Interface - Comunic., Saúde, Educ., v.9, n.16, p.115-29, set.2004/fev.2005.

Este estudio trata de los programas de prevención del consumo de drogas. Se parte del supuesto que en Brasil, principalmente a partir de la década del 1990, se procesaron cambios significativos en las prácticas de prevención. El análisis sistemático de la bibliografía puede contribuir con una evaluación de los rumbos que esas prácticas vienen tomando además de favorecer la crítica y la formulación de nuevos proyectos. El objetivo de este estudio fue: reunir y analizar los trabajos publicados en Brasil, cuyo objeto es la prevención del consumo de drogas en el período de 1991 a 2001. La metodología comprendió dos procedimientos: relevamiento bibliográfico en bancos de datos on-line, utilizando el descriptor prevención de drogas y análisis de los trabajos seleccionados según: tipo de publicación; objetivo del trabajo; enfoque teórico y caracterización de otros elementos internos al desarrollo de los proyectos de prevención propiamente dichos. Los resultados mostraron que la mayor parte de los textos seleccionados tiene el objetivo de proporcionar orientaciones para la prevención, utilizando un enfoque que se orienta en grados diferentes a las concepciones y estrategias de la reducción de daños. Los trabajos que tratan del desarrollo de proyectos se encuentran principalmente en el eje Rio-São Paulo; cerca de la mitad se vale de estudios epidemiológicos o de mecanismos de evaluación propios; la mayor parte busca brindar informaciones a estudiantes y profesores.

PALABRAS CLAVE: Prevención; drogas; publicaciones periodicas. 


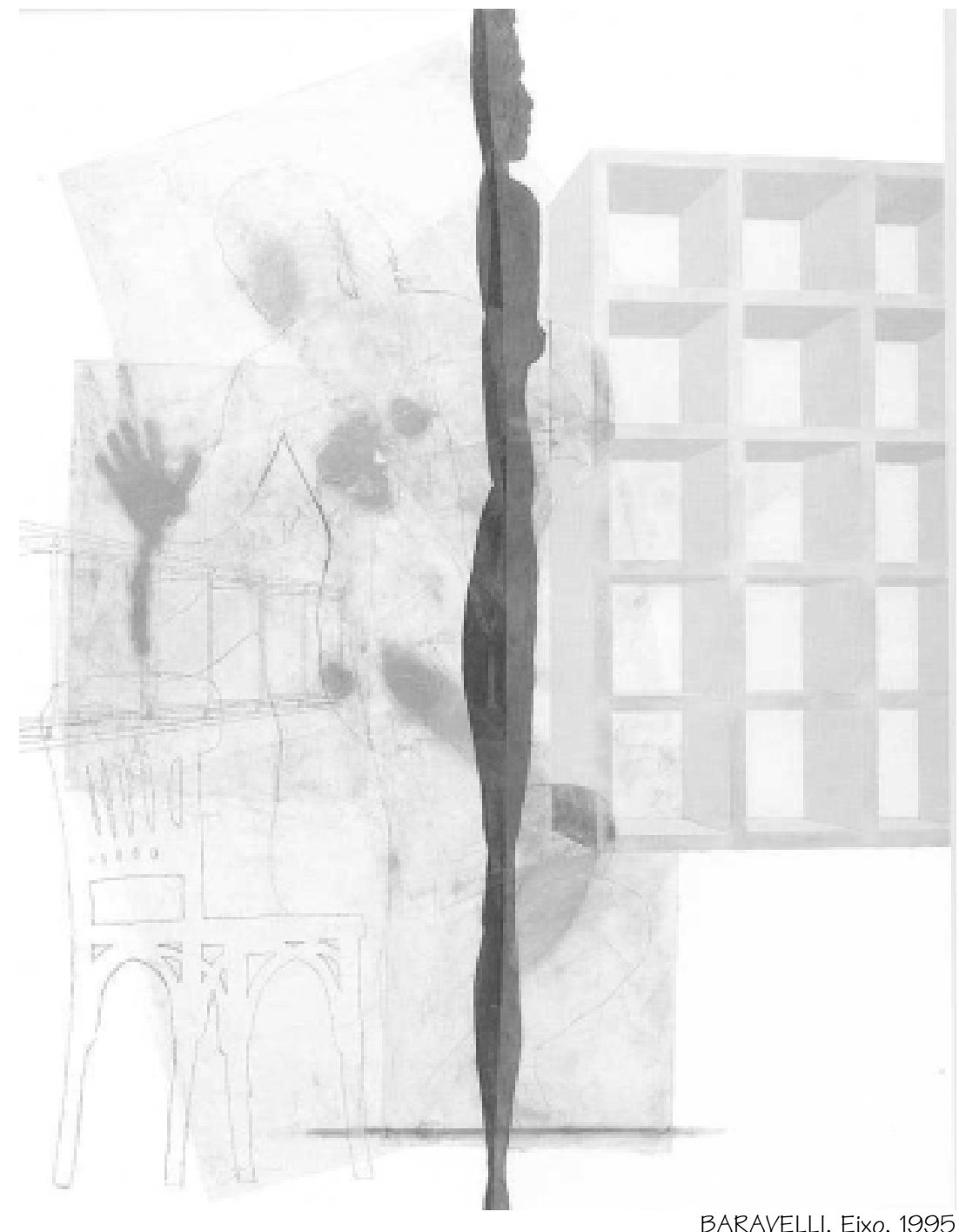

BARAVELLI, Eixo, 1995 